\title{
Endophthalmitis following intravitreal anti-vascular endothelial growth factor (VEGF) injection: a comprehensive review
}

\author{
Rohan Merani ${ }^{1,2,3,4^{*}}$ and Alex P Hunyor ${ }^{1,2,3,5}$
}

\begin{abstract}
The purpose of this review is to report and summarize previously reported studies and assess many of the individual steps of the intravitreal injection procedure's possible effect on the prevention of endophthalmitis. The pooled endophthalmitis rate from 20 large retrospective case series of anti-VEGF injections was 144/510,396 (0.028\%; $1 / 3,544)$. Injections may be performed in an office-based location or in an operating room (OR) and low rates of endophthalmitis can be achieved in either location with careful attention to asepsis. Pre- or post-injection topical antibiotics have not been shown to be effective, and could select for more virulent microorganisms. Povidone-iodine prior to injection is accepted as the gold-standard antiseptic agent, but aqueous chlorhexidine may be an alternative. Antisepsis before and after gel or subconjunctival anesthetic is suggested. The preponderance of Streptococcal infections after intravitreal injection is discussed, including the possible role of aerosolization, which can be minimized by using face masks or maintaining silence. As with other invasive procedures in medicine, the use of sterile gloves, following adequate hand antisepsis, may be considered. Control of the eyelashes and lid margin is required to avoid contamination of the needle, but this can be achieved with or without a speculum. Techniques to minimize vitreous reflux have not been shown to reduce the risk of endophthalmitis. Same day bilateral injections should be performed as two separate procedures, preferably using drug from different lots, especially when using compounded drugs.
\end{abstract}

Keywords: Endophthalmitis, Intravitreal injection, Anti-VEGF, Streptococcus, Masks, Antisepsis, Povidone-lodine, Chlorhexidine, Antibiotics, Speculum

\section{Introduction}

Intravitreal injection (IVI) is the most commonly performed ophthalmic procedure. In the USA, the number of injections performed has increased exponentially, from 4,215 injections in 2001 to 82,994 in 2004 , to 812,413 in 2007, to 1.27 million in 2009 and to 2.5 million injections in 2011 [1, 2]. Similar increases have been observed in Canada and the United Kingdom [3, 4].

Infectious endophthalmitis (IE) secondary to IVI is a potentially devastating complication. It can be difficult to distinguish infectious endophthalmitis from "sterile" or non-infectious endophthalmitis. For the purpose of this review, IE refers to endophthalmitis that is clinically

\footnotetext{
*Correspondence: rmerani@med.usyd.edu.au

${ }^{1}$ Retina Associates, Level 4, 8 Thomas St, Chatswood, NSW 2067, Australia Full list of author information is available at the end of the article
}

suspected to be infectious, and treated as such with a vitreous tap and injection of antibiotics and/or vitrectomy surgery.

Bacteria are most likely inoculated into the vitreous cavity at the time of injection, or much less likely gain access later through the needle tract $[5,6]$. The potential sources of bacteria include the patient's ocular or periocular surfaces, aerosolized bacteria, or contamination of the needle, instruments, drug or drug vial [7].

Two meta-analyses including both retrospective series and clinical trials have calculated the pooled rate of endophthalmitis after anti-VEGF injections. McCannel found a rate of 52/105,536 injections $(0.049 \% ; 1$ in 2030) [8] and more recently, Fileta et al. [9] calculated a rate of $197 / 350,535(0.056 \% ; 1$ in 1,779). As patients typically receive ongoing intravitreal therapy, the per-patient risk

\section{Biomed Central}

(C) 2015 Merani and Hunyor. This article is distributed under the terms of the Creative Commons Attribution 4.0 International License (http://creativecommons.org/licenses/by/4.0/), which permits unrestricted use, distribution, and reproduction in any medium, provided you give appropriate credit to the original author(s) and the source, provide a link to the Creative Commons license, and indicate if changes were made. The Creative Commons Public Domain Dedication waiver (http://creativecommons. org/publicdomain/zero/1.0/) applies to the data made available in this article, unless otherwise stated. 
of endophthalmitis is significantly higher than the perinjection risk.

The rate of needle contamination after IVI has been reported as between 0.36 and $18 \%$, which is significantly higher than the incidence of endophthalmitis after IVI $[5,7,10]$. The threshold inoculum size required to develop endophthalmitis is related to the type of bacteria and their virulence, intraocular immune mechanisms and anatomical characteristics of the vitreous $[11,12]$. Animal studies have shown that a smaller number of bacterial colony-forming units are required to induce endophthalmitis when injected into the vitreous compared to when they are injected into the anterior chamber [13]. Endophthalmitis following intravitreal injection often presents earlier than after cataract surgery $[14,15]$.

The purpose of this review is to estimate the rate of endophthalmitis after intravitreal injection and to examine each step of the injection procedure that may influence the risk of endophthalmitis. To be able to prove that a particular measure reduces the risk of endophthalmitis would need huge numbers of patients in a randomized controlled trial, given that endophthalmitis is a relatively rare outcome. There is thus no Level 1 evidence for any preventative measure to reduce the incidence of endophthalmitis after intravitreal injection. As a result, this review largely summarizes retrospective papers, with their inherent biases.

\section{Methods}

A systematic literature search of the Medline database from 1996 to December 2014 was performed through Ovid, using search terms relevant to each section. Further literature was sourced from the reference lists of retrieved publications.

To estimate the per-injection rate of endophthalmitis after anti-VEGF injection, retrospective case series with at least 10,000 such injections were included. Studies that did not report a breakdown of the drugs used were excluded to avoid including triamcinolone and other injections in this calculation. Questionnaire-based and population-based studies were excluded given the incomplete data. Clinical trials were excluded as they may not reflect real-world practice, with more stringent requirements regarding injection technique often included in the protocols.

\section{Results}

Twenty retrospective case series meeting the inclusion criteria were identified. Details of the injection procedure and associated aseptic measures used in each series are summarized in the Table 1 . Where data were missing, the corresponding author for each study was contacted by email. Only two authors were not contactable.

We identified 144 cases of endophthalmitis from 510,396 anti-VEGF injections which equates to a pooled endophthalmitis rate of $0.028 \%$ or 1 in 3,544 injections [16-33].

\section{Review}

\section{Location-office vs operating room (OR)}

In the 2013 American Society of Retinal Specialists (ASRS) Preferences and Trends (PAT) Survey, over 98\% of USA-based specialists reported performing injections in an office setting, compared with only $47 \%$ of international specialists [34]. In Germany and other parts of Europe, more injections are performed in the operating room $(\mathrm{OR})[35,36]$.

It has been [29] suggested that an advantage of the OR location is the superior air circulation systems. However, the ESCRS endophthalmitis study group was not able to find a relationship between the number of air changes per hour and the incidence of endophthalmitis after cataract surgery when they compared locations with minimal airflow, 20 air changes per hour and ultraclean air systems using laminar flow principles [37, 38].

Pooling the results of three OR-based injection series, the endophthalmitis rate was just $6 / 78,506(0.0076 \%$ or 1 in 13,084) $[19,23,25]$. Common to these studies was the careful attention to asepsis with the use of sterile gloves, face masks, and drapes which were not used in most other office-based series (see Table 1). A notable exception is Shimada et al's series with no cases of endophthalmitis out of 15,144 injections where similar strict aseptic measures were followed in an office setting [27].

Abell et al. [29] reported an endophthalmitis rate of $4 / 3,376(0.12 \%)$ for office-based injections compared with $0 / 8,873(0 \%)$ for OR-based injections. In this nonrandomized series, patients with private health insurance were treated in the OR while those without insurance were treated in the office. The difference in endophthalmitis rates may be a reflection of socioeconomic or other factors [39]. Tabendeh et al. [30] reported an endophthalmitis rate of $3 / 8,210(0.037 \%)$ anti-VEGF injections in the office compared with $2 / 3,047$ in the operating room $(0.066 \%)$, in another non-randomised study that was not powered to be able to detect a difference. Compared with office-based injections, there was no apparent benefit to an OR environment in this small study.

Although there is no doubt that the OR has many advantages, there are logistical hurdles that make access to OR facilities difficult for many patients, and the OR location 







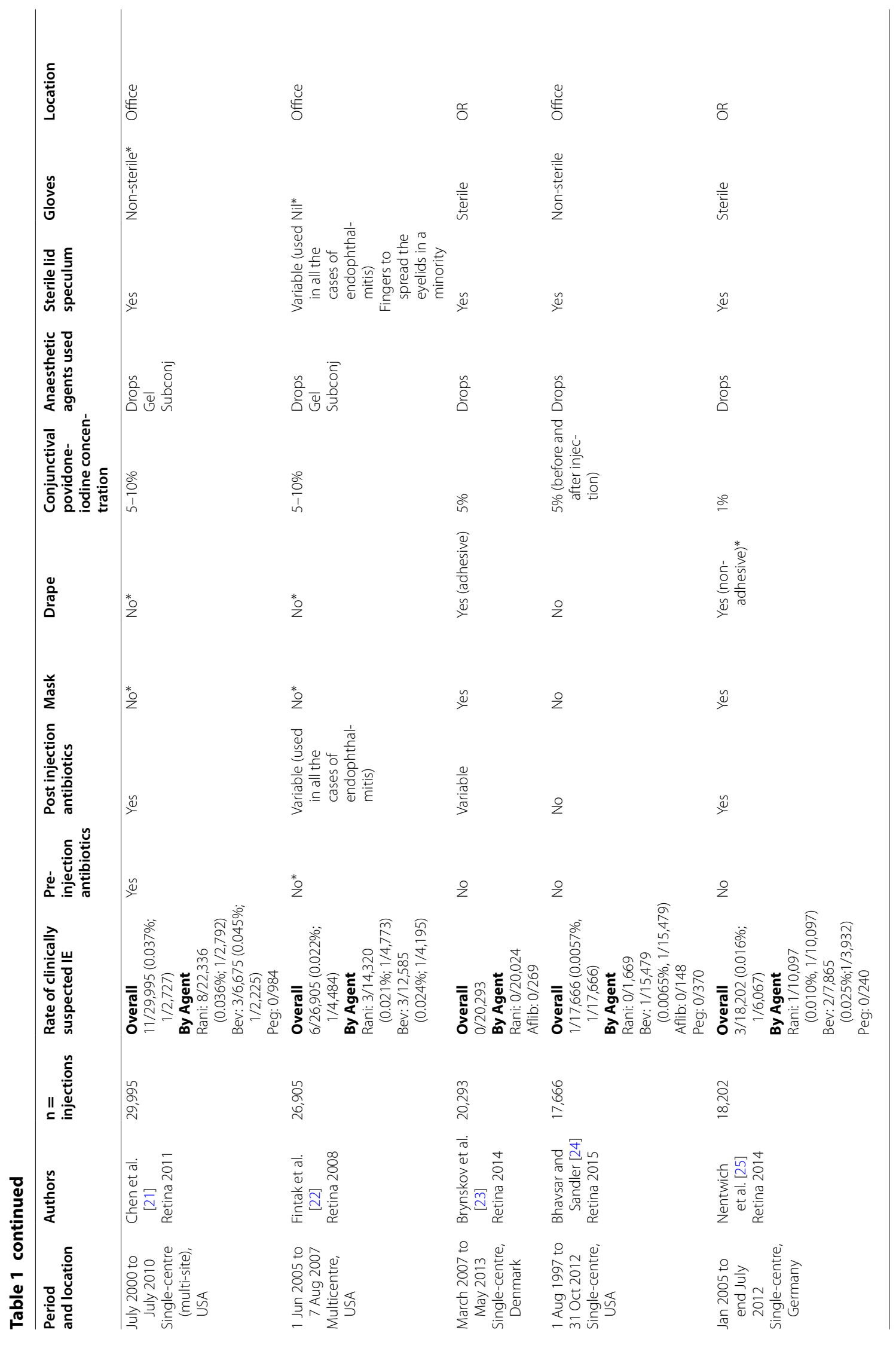




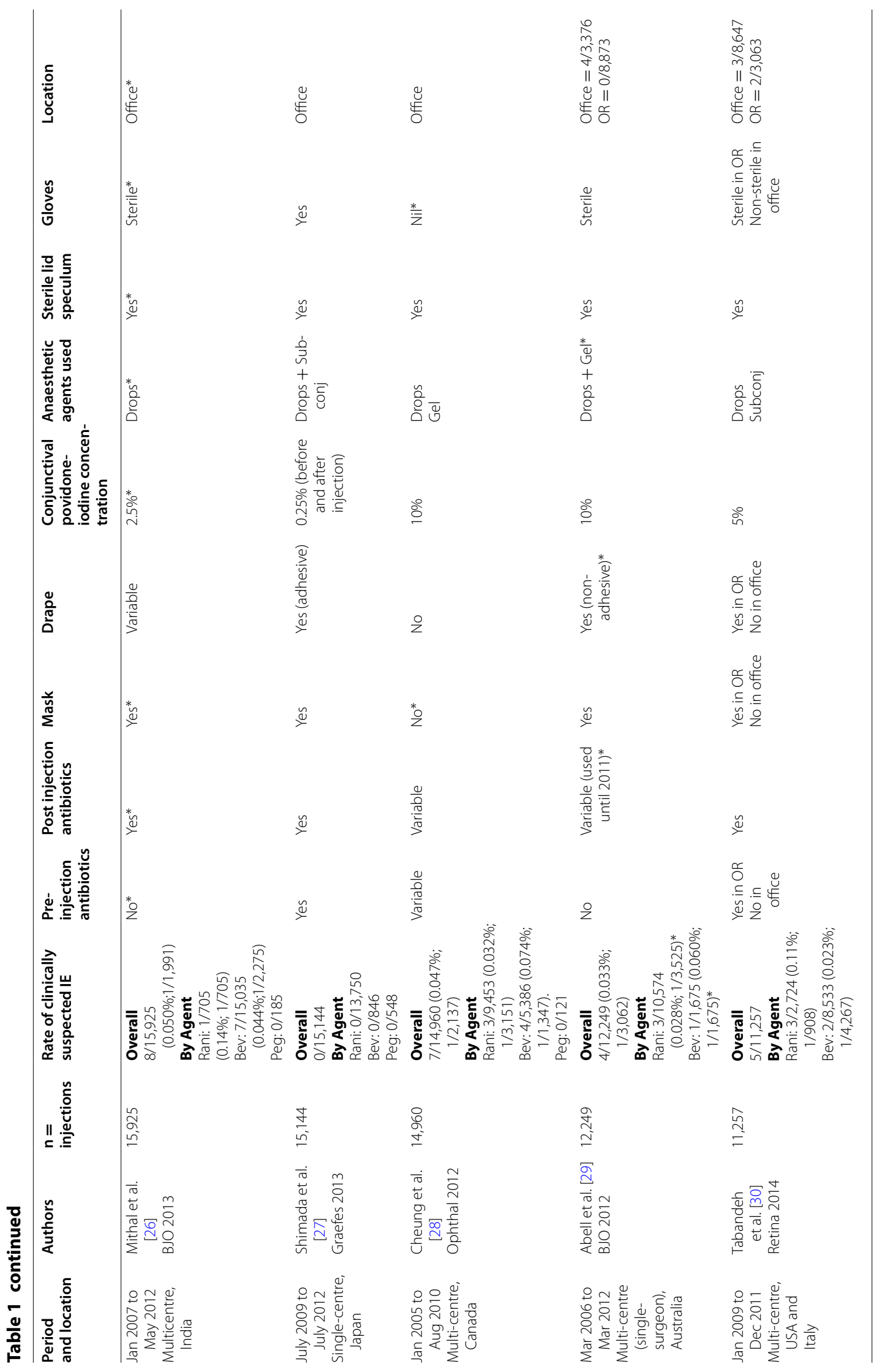




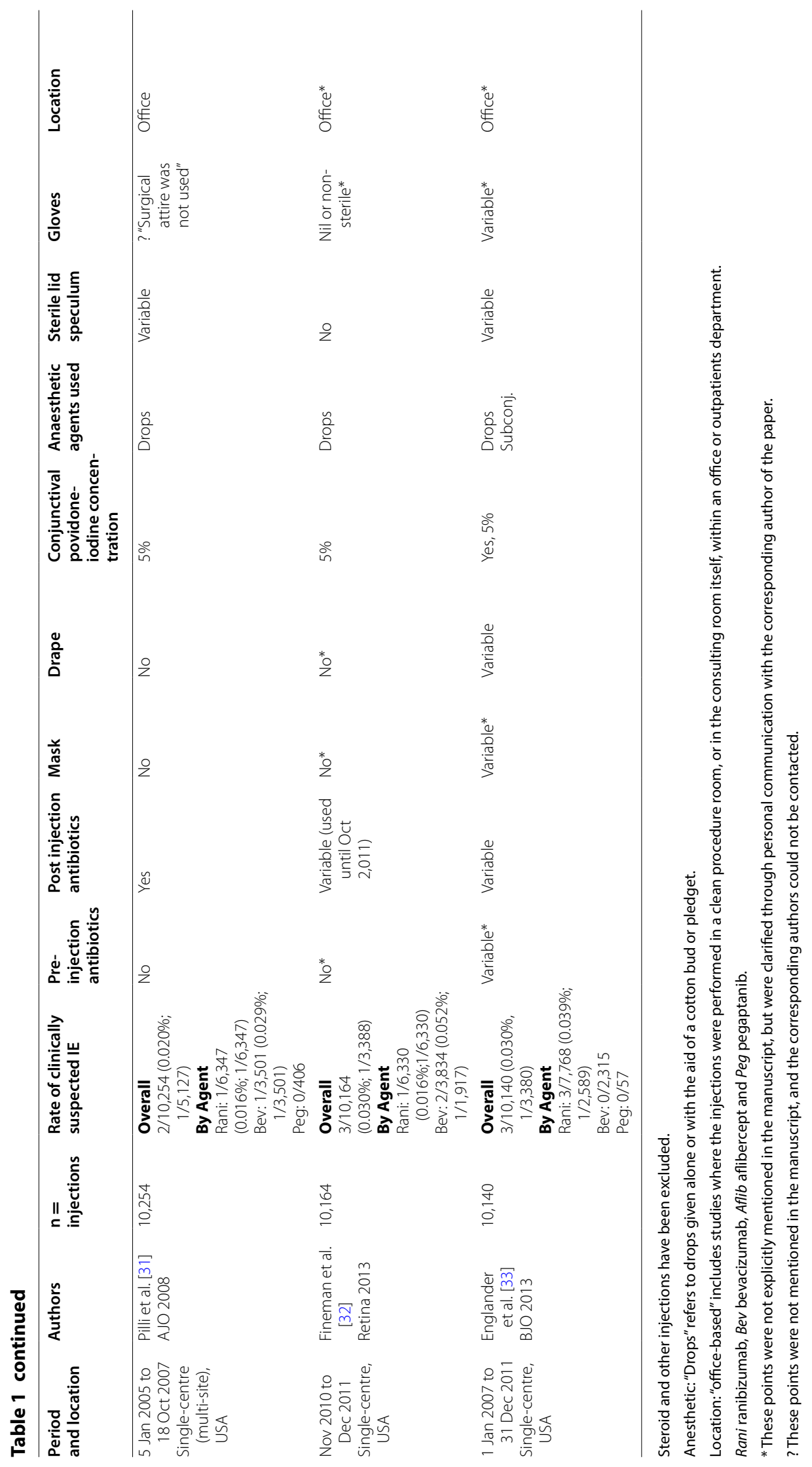


can add substantial additional cost to patients and the healthcare system. It has been suggested that simply being in an OR may alter behavior with more careful attention to asepsis [23]. While three series describing OR-based injections have reported low rates of endophthalmitis, this may reflect publication bias. Similar low rates can be achieved with strict asepsis in an office setting.

\section{Hand antisepsis}

The aim of surgical hand antisepsis is to reduce the bacterial load at the commencement of a procedure. Broadly speaking there are two main types of antisepsis solutions: aqueous scrubs (povidone iodine, chlorhexidine and triclosan) and liquid or gel alcohol rubs (with or without additional ingredients) [40].

Alcohol-based rubs have been found to have superior antimicrobial efficacy compared with aqueous scrubs [40, 41]. The reduction in microbial counts with alcohol rubs is rapid, and inhibition of bacterial regrowth to baseline levels can take more than $6 \mathrm{~h}$ [42]. However, unlike chlorhexidine, alcohol does not bind to the skin imparting a true residual effect, so chlorhexidine or other agents are often added to alcohol rubs [40].

While chlorhexidine induces less allergic reactions than povidone-iodine, skin irritation, dryness and irritant contact dermatitis still occurs more frequently with chlorhexidine scrubbing than with alcohol-based rubs [40, 43]. Liquid alcohol-based rubs are superior to gels both in terms of tolerability and efficacy [44].

Alcohol-based rubs are not without limitations. They do not remove surface dirt because they do not contain surfactants or have a foaming action, and may have limited effectiveness if the hands are heavily contaminated [40, 45]. Rubs may also leave a residue on the hands after use.

There is no specific evidence regarding the role of hand antisepsis in the context of intravitreal injection and most of the retrospective series do not even mention if or how hand antisepsis was performed. If sterile gloves are employed, the need for hand antisepsis could be questioned given the low risk of glove perforation during procedures of very short duration. In our opinion, attention to hand antisepsis is important for all invasive procedures in medicine. The initial antisepsis at the start of an injecting session should ideally include hand washing with soap or an aqueous scrub to mechanically remove any surface dirt or heavy bacterial contamination, especially if gloves are not worn [40, 46]. For subsequent antisepsis, alcohol-based rubs are ideal given their rapid action and superior dermal tolerance.

\section{Gloves}

The purpose of wearing gloves during invasive procedures is to protect both the patient and the surgeon [47].
In a survey of retinal specialists in the USA, only 254/762 (33\%) reported wearing sterile gloves for intravitreal injections, while 323/762 (42\%) did not wear gloves at all [48]. In another smaller survey of 158 retinal specialists, $46 \%$ reported that they do not wear gloves [49]. In contrast, $88 \%$ of 112 surveyed retinal specialists in the United Kingdom reported using sterile gloves [50]. If non-sterile gloves are used, perforations may be more common with vinyl compared with latex gloves [51-53]. Non-sterile gloves may be more prone to fungal contamination compared with individually sealed sterile gloves [54].

It has been argued that sterile gloves are not required as long as the tip of any instrument touching the eye remains sterile $[48,55,56]$. By definition, this is no longer "aseptic technique", a key principle of which is that any part of an instrument if touched directly or indirectly could result in infection [57]. Sterile gloves are required for aseptic procedures, while non-sterile gloves suffice for clean procedures [57]. A "no-touch" technique without gloves at all was advocated for cataract surgery over 50 years ago, but has fallen out of favor [58].

Wound infection rates have been shown to be no higher with the use of non-sterile compared with sterile gloves when suturing the skin $[59,60]$ However, sterile gloves are recommended for the insertion of central venous catheters and spinal anesthesia procedures [51, 61, 62]. Like the CSF, the vitreous is an immune-privileged site and a small inoculum of low virulence bacteria may be sufficient to cause endophthalmitis.

There are no studies directly examining the role of sterile gloves in reducing the risk of post-injection endophthalmitis, and they are often used in conjunction with other aseptic measures such as face masks and sterile drapes. We believe that intravitreal injection should be regarded as an aseptic procedure given that it involves penetration into an immune-privileged, nutrient-rich cavity. Similar to other aseptic procedures in medicine, the use of sterile gloves should be considered.

\section{Masks}

The main purpose of wearing a surgical face mask is to reduce bacterial contamination of the surgical field from the surgeon's mouth or nasopharynx [63]. In the 2013 ASRS PAT survey, just 14\% of US-based ophthalmologists reported wearing a mask and asking the patient not to speak [34].

In his meta-analysis of 105,536 injections, McCannel found that eight of the 26 culture-positive cases (31\%) were due to Streptococcus and noted that this was 3-fold higher than earlier studies of endophthalmitis after cataract surgery [8]. Others have found similar results and have highlighted the poor visual outcomes associated with this virulent pathogen, with an increased likelihood 
of a final VA of counting fingers or less and an increased likelihood of enucleation [14, 16, 17, 21, 64].

It is thought that the preponderance of Streptococcal isolates may relate to droplet dispersal of organisms while performing intravitreal injections. Viridans group Streptococcus species are normal commensals of the upper respiratory tract and oral cavity $[65,66]$. As they are uncommonly found as part of the normal conjunctival flora, it has been suggested that they may contaminate the conjunctival surface or needle via aerosolization, leading to endophthalmitis $[8,21]$. In studies where conjunctival cultures were taken in treatmentnaïve eyes, the most commonly cultured organisms were coagulase negative Staphylococci accounting for $65-83 \%$ of isolates, while $0-7 \%$ of isolates were Streptococci $[6,67-69]$.

In an experimental study designed to simulate the conditions during intravitreal injections, Wen et al. [70] found that wearing a face mask or remaining silent significantly decreased culture plate contamination compared with not wearing a face mask or turning the face away. They also showed that a significant number of colonies grew when the reclined volunteer (simulating a patient) continued talking. While no Streptococcal species were isolated from the groups wearing a face mask or remaining silent, the proportion of bacterial colonies represented by oral Streptococcal species ranged from 67 to $83 \%$ in the other groups.

In a similar study, Doshi et al. [71] also found almost no bacterial growth when a mask was not worn and silence was not maintained, if the agar plates were pretreated with povidone-iodine (PI). In practice however, if the conjunctival surface were to be contaminated immediately prior to needle entry, there may not be adequate time for the PI to take effect.

Friedman et al. [72] recently demonstrated no difference in the needle contamination rates when speaking compared with maintaining silence.

Oral commensals have been found in cases of iatrogenic meningitis following dural puncture procedures and in some cases have been molecularly matched with strains found in the oropharynx of the proceduralist [7376]. Absence of a face mask has also been implicated in iatrogenic septic arthritis after intraarticular injections $[77,78]$. In these cases there is a strong suggestion that airborne transmission of a proceduralist's oropharyngeal flora onto a needle or patient's skin is followed by inoculation into a sterile compartment.

The presence of a viral upper respiratory tract infection (URTI) has been shown to markedly increase the airborne dispersal of methicillin-resistant Staphylococcus aureus (MRSA), which can be prevented by wearing a mask [79].
Several studies have shown that wearing a mask does not lower the risk of surgical wound infection [80-82]. Wen et al. argue that oral Streptococcal species are of relatively low virulence in the immunocompetent host, which is why they are infrequently found in surgical site infections. However the vitreous and cerebrospinal fluid are immune-privileged sites where these usually less virulent strains can flourish [70,77, 83]. Dural puncture is a procedure similar to intravitreal injection in that both involve needle penetration into a nutrient-rich body cavity that can serve as a culture medium [8].

Of course, there may be other explanations for the preponderance of Streptococcal infections after intravitreal injections. Delayed-onset bleb-related endophthalmitis is also associated with a disproportionately higher rate of Streptococcal infection. This may be the result of alterations in the resident flora or structural changes in the eye wall, and such changes may also occur in some eyes after multiple intravitreal injections [30, 84-86].

While the use of face masks has not been proven to reduce the risk of post-injection endophthalmitis [87], they have been associated with a reduction in post-operative endophthalmitis [88]. Although maintaining total silence may be equivalent to the wearing of a mask, it is often important to give patients reassurance and instructions while performing the procedure [89-91]. A mask may also offer protection in the event of an inadvertent cough or sneeze. The needle should remain capped until immediately before the injection [21]. Patients should be instructed to minimize talking before or during the procedure. Assistants involved in setting up the instruments, drug and sterile trays should maintain silence or wear a face mask, and keep the trays covered until the commencement of the procedure. Patients' relatives should be encouraged to wait outside the procedure room.

\section{Antisepsis}

The aim of antisepsis is to reduce the bacterial load on the ocular surface and the periocular structures including the eyelids and eyelashes, without inducing antimicrobial resistance or selecting for more virulent organisms [92]. No study to date has found a correlation between the number of bacteria on the ocular surface and the risk of developing endophthalmitis [93]. Antibiotic resistance does not appear to impair the utility of PI and chlorhexidine, the two most commonly used antiseptics [94].

\section{Povidone-iodine (PI)}

PI is a complex of iodide and a solubilizing carrier, polyvinylpyrrolidone, which acts as a reservoir of "free" iodine, which is the active component [95]. The iodine penetrates bacterial cell membranes and inactivates key cytosolic proteins, fatty acids and nucleotides. PI does 
not have to be allowed to dry or evaporate to have a bactericidal effect [96]. It has a broad spectrum of antimicrobial activity with negligible bacterial resistance [97]. A recent survey found that over $99 \%$ of retinal specialists use PI before intraocular injections [48].

Efficacy In a small randomized study, 5\% PI instilled into the conjunctival sac prior to ophthalmic surgery reduced the number of bacterial colonies by $91 \%$, compared with a 33\% reduction in control eyes [98].

In a subsequent open-label non-randomized parallel trial, Speaker and Menikoff found that the incidence of culture-positive endophthalmitis was $0.06 \%$ in an operating suite using $5 \% \mathrm{PI}$, compared with $0.24 \%$ in another suite using silver protein solution $(\mathrm{P}<0.03)$ [99].

Safety and toxicity Adverse reactions to PI are usually the result of an irritant effect that is proportional to the duration of exposure, and consequently many patients report post-injection pain [100, 101]. A study in rabbits demonstrated significant epithelial fluorescein staining with 5\% PI [102]. It should be irrigated thoroughly postinjection to minimize discomfort [100]. Less commonly, contact dermatitis may develop after repeated exposure $[100,101]$.

If PI is applied to the surface of the eye just before the needle is inserted through the pars plana, a small amount of PI may be introduced into the vitreous cavity [103]. Animal studies have shown that intravitreal injection of a small volume of low-concentration PI is well tolerated $[104,105]$.

Anaphylaxis to PI is rare, and there have been no reports of anaphylaxis following the topical ophthalmic use of PI [100, 103]. Furthermore, seafood allergy is not a contraindication to the use of topical PI, nor is reported allergy to iodinated contrast media [100]. Iodine is not the allergenic component of shellfish or contrast media, even though both contain iodine $[100,101,106]$.

Method of instillation A $10 \mathrm{~mL}$ flush of PI onto the conjunctival surface and fornices has been shown to lower conjunctival bacterial counts more than simply instilling a few drops [93, 107]. Flushing is thought to dislodge bacteria from the fornices, where the conjunctiva has many deep crypts, allowing PI to kill the organisms [93]. Selectively flushing one quadrant of the conjunctival surface while avoiding the cornea has not been compared with bathing the entire ocular surface. While PI may be applied to the eyelid margins and eyelashes, eyelid scrubbing should be avoided [108, 109].

Concentration and contact/kill-time Half-strength (5\%) PI is commonly used on the ocular surface to reduce its epithelial toxicity, but the most effective concentration is debatable [110].

Berkelman et al. [111] demonstrated that diluting fullstrength (10\%) PI paradoxically increased its bactericidal activity against $S$. aureus in vitro. After a $15 \mathrm{~s}$ exposure to PI, no organisms were recovered using concentrations of $0.1,0.2$ or $1 \%$ PI, but sterility was not achieved with such a short exposure using $5 \%$ or $10 \%$ PI. A 1-2 min exposure to $5 \% \mathrm{PI}$ and a 4 min exposure to $10 \% \mathrm{PI}$ was required to achieve sterility.

Ta et al. [112] found no difference in the conjunctival culture rates using 5\% PI for 1 min, compared with $10 \%$ PI for 5 min. Van Rooij et al. [113] reported no increase in their rate of post-cataract surgery endophthalmitis, after switching from 5 to $1 \%$ PI. Shimada et al. [27] described a series of 15,144 injections using $0.25 \%$ PI, without a single case of endophthalmitis.

In contrast, using a 2-min contact time, Ferguson et al. [110] found that 5\% PI was more effective than 1\% PI at reducing the number of colony forming units, particularly in the presence of a heavier initial bacterial load. While the concentration of free iodine may be higher at lower concentrations of PI, it is thought that a lower concentration of PI has a lower reservoir of available iodine, which is exhausted when the bacterial load is increased.

Friedman et al. [114] found a significant reduction in conjunctival bacterial growth after a $30 \mathrm{~s}$ exposure to $5 \%$ PI, and a further reduction with a $60+$ second exposure, while $15 \mathrm{~s}$ was inadequate.

Post-injection antisepsis Post-injection PI may reduce the risk of subsequent bacterial entry via a "vitreous wick" through the wound track. The role of this potential mechanism for endophthalmitis is unclear. Apt et al. [115] showed that 5\% PI instilled at the conclusion of cataract surgery suppressed bacterial growth more than an antibiotic solution, for $24 \mathrm{~h}$ following surgery. Shimada et al. [27] used a $5 \mathrm{~mL}$ flush of $0.25 \%$ PI before and after injections with an endophthalmitis rate of 0/15,144.

Resistance Hsu et al. recently showed that bacterial resistance does not develop in patients undergoing serial intravitreal injections with povidone-iodine preparation alone, without the use of pre- or post-injection topical antibiotics, confirming previous in vitro work [116-118].

\section{Aqueous chlorhexidine}

Chlorhexidine is a cationic biguanide that damages the outer bacterial surface layers and subsequently attacks the cytoplasmic membrane of the organism [95]. Chlorhexidine, like PI, is a broad-spectrum antimicrobial agent. Compared with PI, chlorhexidine may act less rapidly, but exhibits sustained antimicrobial activity, 
and is not readily neutralized by organic matter [95, 119].

Efficacy The mean reduction in conjunctival bacterial counts prior to corneal suture removal using a $3 \mathrm{~min}$ exposure to $4 \%$ PI was $91 \%$, compared with $88 \%$ using $0.05 \%$ chlorhexidine, a non-statistically significant difference [120]. In another study, there was no difference in the culture rate from conjunctival swabs in patients receiving either $0.05 \%$ chlorhexidine or $0.6 \%$ PI [121].

In a multi-center retrospective study where aqueous chlorhexidine gluconate $0.1 \%$ was used as the sole antiseptic measure prior to intravitreal injection, the endophthalmitis rate was $3 / 40,535(0.0074 \%$; 1 in 13,512$)$ [Personal communication, Dr Peter Davies, Newcastle, NSW Australia].

Safety and toxicity The safety of aqueous chlorhexidine has been detailed in numerous animal studies [122-124], however alcohol-based or detergent-based chlorhexidine causes severe corneal epithelial toxicity [125]. Topical chlorhexidine $0.02 \%$ to $0.2 \%$ is used as a treatment for acanthamoeba keratitis [126]. While endothelial toxicity is well described, a significant concentration of chlorhexidine is unlikely to reach the endothelium after intravitreal anti-VEGF injection [127-129].

Resistance The acquisition of resistance to chlorhexidine has been demonstrated in vitro but whether it occurs on the ocular surface after repeated intravitreal injections is yet to be studied [117]. The reduced susceptibility of methicillin-resistant $S$. aureus (MRSA) to chlorhexidine compared with methicillin-sensitive $S$. aureus, and the presence of efflux-mediated resistance genes in staphylococci is of concern [130].

\section{Povidone-lodine + chlorhexidine}

Synergy when using both PI and chlorhexidine has been described in vitro and in clinical studies on the skin, but has not been studied on the eye $[95,131,132]$.

\section{Saline irrigation alone}

Irrigation with saline alone has been shown to be ineffective in reducing the conjunctival bacterial load and may even increase bacterial counts, perhaps because bacteria are dislodged from the fornices but not subsequently killed. [114, 133, 134]

In summary, the optimal concentration and contacttime for antiseptic agents likely depends on the bacterial load, the spectrum of bacteria present and their virulence, and the robustness of the host defense mechanisms. While a longer contact time may lead to a greater reduction in the bacterial load, it may be complicated by more epithelial toxicity. With either agent, our practice is to copiously irrigate the ocular surface with normal saline after the procedure, to minimize epithelial toxicity. For patients who have experienced severe pain after an injection we have recommended they use preservative-free lubricants for a day prior to their subsequent injections with good effect.

\section{Anesthesia}

Anesthesia prior to intravitreal injection can be achieved using topical drops (alone or on a sterile cotton-tipped applicator or pledget), viscous gel, subconjunctival injection or a combination of these $[135,136]$. Drops are typically used prior to gel or subconjunctival injection.

\section{Viscous gel anesthesia}

Lidocaine gel has been shown to act as a barrier preventing PI from coming into contact with bacteria on an agar plate [137], and was shown to be a risk factor for postoperative endophthalmitis if applied prior to PI [138]. No cases of endophthalmitis were found in a series of 4,690 injections where PI was instilled both before and after application of lidocaine $2 \%$ gel [139]. In vitro, application of PI for a mere $5 \mathrm{~s}$ prior to lidocaine gel application has been shown to be effective in inhibiting bacterial growth [140].

In contrast, Dahl et al. [141] found reduced colony forming units in eyes when lidocaine $2 \%$ gel was applied before PI, compared with when PI was used alone $(\mathrm{P}=0.08)$. Lidocaine gel plated with $S$. aureus and Escherichia coli showed a ring of inhibition to both bacteria, suggesting that lidocaine gel might independently exert an antimicrobial effect. Lad et al. found no difference in the post-injection endophthalmitis rate when lidocaine gel was applied prior to PI $(4 / 4,682 ; 0.085 \%)$, compared to when PI was used alone $(4 / 4,120 ; 0.097 \%)$ $(\mathrm{P}=1.00)$ [142]. Although gel may act as a complete barrier to antiseptic agents on an agar plate, the ocular surface is warm, has continuous tear production and there is movement between the globe and the eyelid, all of which aid the dispersal of gel.

\section{Subconjunctival anesthesia}

In a retrospective series, Tustin et al. reported a rate of endophthalmitis of $8 / 8,189(0.1 \%)$ when subconjunctival lidocaine was not used, compared with $0 / 6,853$ when it was used $(P=0.03)$, suggesting that the use of subconjunctival anesthetic may reduce the risk of endophthalmitis [143]. However, 14 culture-negative cases of "possible" endophthalmitis were excluded, nine of which were after injection of triamcinolone and five after bevacizumab. The same authors found that $2 \%$ lidocaine $/ 0.1 \%$ 
methylparaben demonstrated rapid bactericidal effects against $S$. aureus, S. epidermidis and S. viridans in vitro [143].

If antiseptics are not used prior to administration of subconjunctival anesthetic, surface bacteria may be introduced into the subconjunctival space by the needle, and these could in turn be introduced into the vitreous cavity [144]. Nonetheless, Tustin et al. [143] only applied PI after the subconjunctival injection of anesthetic, and not before, with no cases of definite endophthalmitis.

While lidocaine may have inherent bactericidal properties, the reduction in endophthalmitis risk with subconjunctival lidocaine that Tustin et al. reported may be the result of other factors. The bleb of anesthetic may help to disconnect the vitreous body from the conjunctival surface, or dilute the pathogens that are present. As subconjunctival anesthesia works best if left for at least a few minutes, it allows the povidone-iodine to remain in contact with the ocular surface for longer than usual. Finally, adequate anesthesia is crucial so that the patient does not move or squeeze their eyes as the needle enters the eye, as these sudden involuntary responses can compromise the sterility of the needle. With the deeper anesthesia afforded by subconjunctival injection, this may be another explanation for their results.

The application of antiseptic agents before and after gel or subconjunctival anesthetic is important, and any intrinsic antimicrobial activity of lidocaine should not be relied upon. When gel anesthesia is used, the authors remove any residual gel by rolling a sterile cotton-tipped applicator over the conjunctival surface prior to flushing with more PI.

\section{Antibiotics}

In the ASRS PAT Surveys the percentage of respondents using pre-injection antibiotics was $40 \%$ in $2008,39 \%$ in 2009 and $27 \%$ in 2011 [34]. The percentage using them post-injection was $86 \%$ in $2008,82 \%$ in 2009 and $62 \%$ in 2011. In 2013, 78\% of US respondents indicated no use of pre- or post-injection antibiotics.

\section{Pre-injection antibiotics}

There have been no prospective studies showing that preinjection antibiotics reduce the risk of endophthalmitis. Isenberg et al. reported synergy between antibiotics and PI, with sterile conjunctival cultures found in $31 \%$ of eyes treated with a 3 day course of pre-operative antibiotics alone and in $40 \%$ treated with PI alone, compared with sterile cultures in $83 \%$ of eyes that received both antibiotics and PI [145]. However, given the longer kill-time of antibiotics compared with PI, using antibiotics just $1-2 \mathrm{~h}$ pre-operatively conferred no additional benefit over PI alone in two studies [146, 147].

In a study of patients undergoing regular intravitreal injections, the rate of positive bacterial cultures was $8 \%$ in the group that received a 3 day course of pre-injection gatifloxacin in addition to PI, compared with just $4 \%$ in the group that received PI alone $(P=0.32)$ [69]. The lack of synergy may be a reflection of increased antibiotic resistance in patients having regular injections with repeated antibiotic exposure, as compared with patients about to undergo cataract surgery who are relatively antibiotic naive.

\section{Post-injection antibiotics}

Antibiotics have been used post-injection, but not pre-injection, in several series without the prevention of endophthalmitis (see Table 1) [17, 19, 22, 25, 26, 31, 32]. In fact, a non-statistically significant higher rate of endophthalmitis has been found in patients receiving post-injection antibiotics in a number of studies $[16,28$, 148-150].

\section{Antibiotic resistance}

Coagulase-negative Staphylococcus endophthalmitis isolates resistant to fluoroquinolones at Bascom Palmer Eye Institute increased from 0 to $10 \%$ in $1990-1994$, to $17-21.8 \%$ in $1995-1999$, to $26.9-38.4 \%$ in $2000-2004$, to $57.8-60.5 \%$ in $2005-2011$ [151-153]. It is suspected that the widespread use of fluoroquinolones is responsible for the increasing resistance.

In 2010, the Antibiotic Resistance of Conjunctiva and Nasopharynx Evaluation (ARCaNE) investigators reported a significant baseline level of bacterial resistance in the conjunctiva of patients with newly diagnosed choroidal neovascularisation [67]. They subsequently showed that repeated intermittent exposure of ocular flora to topical antibiotics selected for resistant strains, which emerged immediately after exposure to antibiotic, and were maintained by periodic re-exposure $[154,155]$. Co-resistance to other antibiotics also developed [156].

In another study, eyes receiving a 4-day course of fluoroquinolones after each injection were found to have a resistance rate of $87.5 \%$ compared with $25 \%$ in control eyes [157]. In a larger prospective study, a 3-day course of topical moxifloxacin after each injection increased the percentage of resistant isolates from $0 \%$ at baseline to $50 \%$ at month three [68].

In an animal study of experimentally-induced S. epidermidis endophthalmitis, antibiotic-resistant strains caused more inflammation and destruction of the infected retina compared with antibiotic-susceptible strains [158]. The same authors also noted that only antibiotic resistant strains of $S$. epidermidis have been isolated from 
their patients with post-operative endophthalmitis. It is postulated that antibiotic resistance leads to colonization by more virulent bacterial strains that can overcome the host defense mechanisms more easily, resulting in a higher likelihood of endophthalmitis [28, 159]. Antibiotic-resistant strains may also be more difficult to treat.

\section{Antibiotic penetration}

It has been shown that the topical administration of second-generation (ciprofloxacin, ofloxacin) and fourthgeneration (moxifloxacin, gatifloxacin) fluoroquinolones leads to effective levels in the aqueous but not in the vitreous, in the non-inflamed eye $[160,161]$.

In summary, topical antibiotics not only have minimal vitreous penetration and seem to be unhelpful in preventing endophthalmitis, but with increasing resistance and selection of more virulent strains, routine antibiotic use could be harmful and we do not recommend their use either pre- or post-injection. Pre-injection topical antiseptics must be used, and to alleviate post-injection discomfort, patients can use preservative-free lubricants.

\section{Speculum}

It is critically important to avoid contaminating the needle with the eyelashes or lid margins before or during entry into the globe, as direct inoculation is considered to be the major mechanism by which endophthalmitis occurs [108, 162]. A speculum is a reliable way to isolate the injection site, but many patients find them uncomfortable.

In a survey of retinal specialists in the USA, 92\% of respondents stated that they routinely use an eyelid speculum to keep the eyelashes away during intravitreal injections [48]. A closed-blade speculum is superior to an open-blade speculum as it covers the eyelashes more effectively [163], but the most temporal lashes may remain exposed with any speculum. In some patients, excessively long eyebrow hairs also need to be avoided. In eight of the 12 patients with endophthalmitis in the VISION study, the infection was associated with protocol violations, the most common being failure to use an eyelid speculum [162].

Insertion of a speculum could theoretically squeeze secretions and bacteria out of the Meibomian glands, particularly in patients who forcefully squeeze their eyelids against the speculum. For this reason, it has been recommended that further PI should be instilled after speculum insertion $[35,108]$. In a randomized controlled study, Friedman et al. [114] recently showed that the placement of a lid speculum did not in fact increase the number of conjunctival bacterial colony forming units.

Tailor et al. [164] found that the insertion of a lid speculum was the third most uncomfortable step during an intravitreal injection. Fineman et al. [32] found that a two-person bimanual eyelid retraction technique has the advantage of less patient discomfort. In their series of 10,164 injections without the use of a speculum there were three cases of endophthalmitis $(0.03 \%)$. One-person bimanual retraction techniques using the fingers [165], a cotton-tip applicator [166], or a Desmarres lid retractor [167] have recently been described. In the PIE study, the endophthalmitis rate was $13 / 12,500(0.10 \%)$ with the use of a bladed lid speculum, compared with $10 / 15,236(0.066 \%)$ without $(\mathrm{P}=0.27)$ [168].

While the experience in the VISION study made a compelling argument for the use of eyelid speculums, more recent evidence suggests that alternative methods of isolating the eyelids and eyelashes may be acceptable. With or without a speculum, we believe that if a needle has inadvertently touched anything but the bulbar conjunctiva at the injection site before or during entry into the eye it should be immediately withdrawn and discarded to avoid inoculating the vitreous. While PI may be applied to the eyelid margins and eyelashes, the adnexae should still be considered non-sterile.

\section{Sterile drapes}

In a survey of retinal specialists in the USA, 668 of 759 respondents (88\%) reported not using a sterile drape [48]. It has been suggested that a sterile adhesive drape isolates the patient's nose and oropharynx from their eye, and theoretically could reduce bacterial aerosolization originating from the patient $[19,70]$.

In a study evaluating patients' experiences at different stages of the injection procedure, the application, cutting and removal of an adhesive drape were found to be the most uncomfortable aspects of the procedure, bar the injection itself [164].

Sterile drapes allow the physician to position the patient's head without contaminating their sterile gloves. It is unclear how important they are in reducing the risk of endophthalmitis given that their use is often associated with other aseptic measures including the use of sterile gloves and face masks.

\section{Techniques to minimize vitreous reflux}

When an intravitreal injection needle is withdrawn from the eye, a subconjunctival bleb forms in approximately one-third of cases [169]. It is thought to comprise liquefied vitreous as well as some of the injected drug [170-172], but the presence of reflux does not lead to a subtherapeutic effect [173]. There is a theoretical risk of endophthalmitis occurring when organisms gain entry into the vitreous cavity through a "vitreous wick" [174]. Turgut et al. [175] found less vitreous reflux with injections performed through the inferotemporal quadrant compared with the superotemporal quadrant. 
Displacement of the conjunctiva with a sterile cotton tip applicator before injection is thought to provide a disconnect between the vitreous cavity and the external eye, keeping the vitreous wick subconjunctival [35]. In the PIE study this technique was not associated with a reduced risk of endophthalmitis [168]. Inoculation of the vitreous with a cotton fiber has been reported as a complication $[176,177]$. Applying pressure to the injection site immediately after needle withdrawal has also been advocated to help reduce the amount of vitreous reflux [174].

Tunneled injections through the sclera are associated with less vitreous reflux compared with straight injections that enter the sclera perpendicularly [178-180]. The most commonly used needle size for anti-VEGF injections is $30 \mathrm{G}$ [48]. $31 \mathrm{G}$ and $32 \mathrm{G}$ needles have been shown to produce less vitreous reflux in patients [181, 182] and in live rabbits [170], however in one cadaveric study [183] more reflux was found with $32 \mathrm{G}$ compared with $30 \mathrm{G}$ needles.

The reduced vitreous reflux with $32 \mathrm{G}$ needles or tunneled injections is associated with a higher immediate, though transient, intraocular pressure (IOP) elevation $[179,180,184,185]$. Hoang et al. [184] have reported that repeated intravitreal injections in an eye may be complicated by sustained elevations in IOP. They have discussed possible mechanisms by which long-term ocular hypertension could result, and have hypothesized that repeated injections with minimal reflux may cause mechanical expansile stress on the trabecular meshwork.

In summary, techniques to minimize vitreous reflux have not been proven to reduce the risk of endophthalmitis and may be associated with more ocular hypertension.

\section{Disinfection of drug vials}

The pharmaceutical companies and the Centre for Disease Control recommend that the rubber diaphragm of a drug vial should be disinfected with alcohol prior to drawing medication [186].

Buckley et al. [187] found that the diaphragm of one single use vial was contaminated with Staphylococcus epidermidis, while the other 99 they examined were sterile. Hilliard et al. [188] reported contamination of the diaphragm in two out 12 vials, despite an intact dust plastic cover.

In short, disinfection of the rubber diaphragm of vials with an alcohol swab is recommended, but the use of prefilled syringes eliminates this step.

\section{Same day bilateral Intravitreal Injections}

For patients with bilateral disease requiring relatively frequent dosing, bilateral same day injections can reduce the burden of treatment. In the 2013 ASRS PAT survey
$50 \%$ of respondents reported doing same day bilateral injections compared with only $27 \%$ in 2008 [34].

Tabatabaii et al. [189] have reported two cases of bilateral endophthalmitis following bevacizumab, resulting in $20 / 400$ vision bilaterally in one patient and light perception bilaterally in another.

Pooling the results of eight series, out of 3708 episodes of bilateral anti-VEGF injections (7,416 injections), there have been three cases of unilateral culture-positive endophthalmitis, one case of unilateral culture-negative endophthalmitis, and one case of unilateral intraocular inflammation [190-197].

Numerous outbreaks of endophthalmitis after injection with compounded bevacizumab have been reported, and are thought to be due to contamination during syringe preparation at the compounding pharmacy. Goldberg et al. [198] have suggested using bevacizumab syringes from two different batches for bilateral same-day injections.

Given the low risk, bilateral injections appear appropriate in select patients. While bilateral injections should be considered as two separate procedures, with separate instruments and ideally drug from different lots, they cannot be truly independent given that the patient is likely to have similar risk factors in both eyes, for example similar conjunctiva flora [198-200]. The surgeon is likely to employ similar aseptic measures and technique in both eyes and in many centers only one procedure room is available.

\section{Conclusion}

Each step of the intravitreal injection procedure has been examined, and the relative importance of each aspect in lowering the risk of endophthalmitis can be debated at length.

From the available evidence, we believe that antibiotics pre- or post-injection should be omitted, placing further importance upon the need for adequate pre-injection antisepsis, which should be applied both before and after gel or subconjunctival anesthetic. We advocate the wearing of face masks or maintaining silence given the risk of aerosolization of bacteria. Exposure of the injection site can be achieved with or without a speculum and the needle must not make contact with anything before entering the eye. Adhering to strict aseptic technique in an office or operating room may help achieve the goal of lowering the risk of endophthalmitis following intravitreal injection.

The major weakness of this review is that it relies heavily upon retrospective data with the inherent selection biases of such studies. Prospective studies will allow firmer recommendations to be made in the future. 


\section{Abbreviations}

VEGF: vascular endothelial growth factor; OR: operating room; ASRS: American Society of Retinal Specialists; PAT Survey: Preferences and Trends Survey; PI: povidone-iodine; IOP: intraocular pressure.

\section{Authors' contributions}

RM performed the detailed literature review and drafted the manuscript. APH conceived the study, helped to draft the manuscript and revised it critically. All authors read and approved the final manuscript.

\section{Author details}

${ }^{1}$ Retina Associates, Level 4, 8 Thomas St, Chatswood, NSW 2067, Australia. ${ }^{2}$ Save Sight Institute, University of Sydney, Sydney, NSW, Australia. ${ }^{3}$ Australian School of Advanced Medicine, Macquarie University, Sydney, NSW, Australia. ${ }^{4}$ Concord Repatriation General Hospital, Concord, NSW, Australia. ${ }^{5}$ Sydney Eye Hospital, Sydney, NSW, Australia.

\section{Acknowledgements}

The authors thank Catherine Higman, Frances Miechels and Kaye Lee at the Geoff Marel Library, Concord Repatriation General Hospital, Sydney, Australia for their invaluable assistance in sourcing the older literature. The authors also thank the corresponding authors of the series included in Table 1 for their help clarifying the injection techniques used in their studies.

This paper was presented in part at: (1) The Australian and New Zealand Society of Retina Specialists (ANZSRS) Retina Symposium on 3rd June 2012 in Sydney, Australia. (2) The Sydney Eye Hospital Alumni Association 9th Biennial Meeting on 28th July 2012 in Sydney, and was the recipient of the Philip Stoney Award for Best Paper. (3) The Royal Australian and New Zealand College of Ophthalmologists (RANZCO) 44th Annual Scientific Congress on 27th November 2012 in Melbourne, Australia.

\section{Compliance with ethical guidelines}

\section{Competing interests}

Dr Rohan Merani reports no competing financial or non-financial interests. A/ Prof Alex P. Hunyor is on Advisory Boards for Novartis and Bayer Pharmaceuticals, which manufacture ranibizumab and aflibercept respectively.

\section{Received: 3 April 2015 Accepted: 30 June 2015}

Published online: 21 July 2015

\section{References}

1. Ramulu PY, Do DV, Corcoran KJ, Corcoran SL, Robin AL (2010) Use of Retinal procedures in medicare beneficiaries from 1997 to 2007. Arch Ophthalmol 128(10):1335-1340. doi:10.1001/archophthalmol.2010.224

2. Murray TG (2012) Intravitreal Injection techniques: maximizing comfort and minimizing the risk of endophthalmitis. ASRS On-Demand Webinar 19 September 2012. Available at http://www.asrs.org/education/calendar/event/51/on-demand-webinar-intravitreal-injection-techniquesmaximizing-comfort-and-minim. Accessed 22 Nov 2013

3. Campbell RJ, Bronskill SE, Bell CM, Paterson JM, Whitehead M, Gill SS (2010) Rapid expansion of intravitreal drug injection procedures, 2000 to 2008: a population-based analysis. Arch Ophthalmol 128(3):359-362. doi:10.1001/archophthalmol.2010.19

4. Keenan TDL, Wotton CJ, Goldacre MJ (2012) Trends over time and geographical variation in rates of intravitreal injections in England. $\mathrm{Br} \mathrm{J}$ Ophthalmol 96(3):413. doi:10.1136/bjophthalmol-2011-300338

5. de Caro JJ, de Kaspar HM, Ta CN, Ho H-KV, Cabael L, Hu N et al (2008) Bacterial contamination of ocular surface and needles in patients undergoing intravitreal injections. Retina 28(6):877-883. doi:10.1097/IAE.0b013e31816b3180

6. Moss JM, Sanislo SR, Ta CN (2010) Antibiotic susceptibility patterns of ocular bacterial flora in patients undergoing intravitreal injections. Ophthalmology 117(11):2141-2145. doi:10.1016/j.ophtha.2010.02.030

7. Stewart JM, Srivastava SK, Fung AE, Mahmoud TH, Telander DG, Hariprasad SM et al (2011) Bacterial contamination of needles used for intravitreal injections: a prospective multicenter study. Ocul Immunol Inflamm 19(1):32-38. doi:10.3109/09273948.2010.520405
8. McCannel CA (2011) Meta-analysis of endophthalmitis after intravitreal injection of anti-vascular endothelial growth factor agents: causative organisms and possible prevention strategies. Retina 31(4):654-661. doi:10.1097/IAE.0b013e31820a67e4

9. Fileta JB, Scott IU, Flynn HW Jr (2014) Meta-analysis of infectious endophthalmitis after intravitreal injection of anti-vascular endothelial growth factor agents. Ophthal Surg Laser Imaging Retina 45(2):143149. doi:10.3928/23258160-20140306-08

10. Nentwich M, Yactayo-Miranda Y, Weimann S, Froehlich S, Wolf A, Kampik A et al (2009) Bacterial contamination of needle points after intravitreal injection. Eur J Ophthalmol 19(2):268-272

11. Maxwell DP Jr, Brent BD, Orillac R, Baber WB, Mayeux PA (1993) A natural history study of experimental Staphylococcus epidermidis endophthalmitis. Curr Eye Res 12(10):907-912

12. Ranchod TM, Leverenz VR, Chintala SK, Cheng M, Trese MT, Giblin FJ (2010) Re: infectious endophthalmitis after intravitreal injection of antiangiogenic agents. Retina 30(10):1752-1754. doi:10.1097/ IAE.0b013e3181fa4960 (author reply 4)

13. Shockley RK, Jay WM, Fishman PH, Aziz MZ, Rissing JP (1985) Effect of inoculum size on the induction of endophthalmitis in aphakic rabbit eyes. Acta Ophthalmol Copenh 63(1):35-38

14. Simunovic MP, Rush RB, Hunyor AP, Chang AA (2012) Endophthalmitis following intravitreal injection versus endophthalmitis following cataract surgery: clinical features, causative organisms and post-treatment outcomes. Br J Ophthalmol 96(6):862-866. doi:10.1136/bjophthalmol-2011-301439

15. Hoevenaars NE, Gans D, Missotten T, van Rooij J, Lesaffre E, van Meurs JC (2012) Suspected bacterial endophthalmitis following intravitreal anti-VEGF injection: case series and literature review. Ophthalmologica 228(3):143-147. doi:10.1159/000339584

16. Storey P, Dollin M, Pitcher J, Reddy S, Vojtko J, Vander J et al (2014) The role of topical antibiotic prophylaxis to prevent endophthalmitis after intravitreal injection. Ophthalmology 121(1):283-289. doi:10.1016/j. ophtha.2013.08.037

17. Moshfeghi AA, Rosenfeld PJ, Flynn HW Jr, Schwartz SG, Davis JL, Murray TG et al (2011) Endophthalmitis after intravitreal anti-vascular endothelial growth factor antagonists: a six-year experience at a university referral center. Retina 31(4):662-668. doi:10.1097/IAE.0b013e31821067c4

18. Chaudhary KM, Romero JM, Ezon I, Fastenberg DM, Deramo VA (2013) Pars plana vitrectomy in the management of patients diagnosed with endophthalmitis following intravitreal anti-vascular endothelial growth factor injection. Retina 33(7):1407-1416. doi:10.1097/ IAE.0b013e3182807659

19. Casparis H, Wolfensberger TJ, Becker M, Eich G, Graf N, Ambresin A et al (2014) Incidence of presumed endophthalmitis after intravitreal injection performed in the operating room: a retrospective multicenter study. Retina 34(1):12-17. doi:10.1097/IAE.0b013e31829f74b0

20. Klein KS, Walsh MK, Hassan TS, Halperin LS, Castellarin AA, Roth D et al (2009) Endophthalmitis after anti-VEGF injections. Ophthalmology 116(6):1225 e1. doi:10.1016/j.ophtha.2009.02.031

21. Chen E, Lin MY, Cox J, Brown DM (2011) Endophthalmitis after intravitreal injection: the importance of viridans streptococci. Retina 31(8):1525-1533. doi:10.1097//AE.0b013e318221594a

22. Fintak DR, Shah GK, Blinder KJ, Regillo CD, Pollack J, Heier JS et al (2008) Incidence of endophthalmitis related to intravitreal injection of bevacizumab and ranibizumab. Retina 28(10):1395-1399. doi:10.1097/ IAE.0b013e3181884fd2

23. Brynskov T, Kemp H, Sorensen TL (2014) No cases of endophthalmitis after 20,293 intravitreal injections in an operating room setting. Retina 34(5):951-957. doi:10.1097/IAE.0000000000000071

24. Bhavsar AR, Sandler DR (2015) Eliminating antibiotic prophylaxis for intravitreal injections: a consecutive series of 18,839 injections by a single surgeon. Retina 35(4):783-788. doi:10.1097/IAE.0000000000000392

25. Nentwich MM, Yactayo-Miranda Y, Schwarzbach F, Wolf A, Kampik A, de Kaspar HM (2014) Endophthalmitis after intravitreal injection: decreasing incidence and clinical outcome-8-year results from a tertiary ophthalmic referral center. Retina 34(5):943-950. doi:10.1097/ IAE.0000000000000011

26. Mithal K, Mathai A, Pathengay A, Jalali S, Relhan N, Motukupally SR et al (2013) Endophthalmitis following intravitreal anti-VEGF injections in ambulatory surgical centre facility: incidence, management and outcome. Br J Ophthalmol. doi:10.1136/bjophthalmol-2013-303222 
27. Shimada H, Hattori T, Mori R, Nakashizuka H, Fujita K, Yuzawa M (2013) Minimizing the endophthalmitis rate following intravitreal injections using $0.25 \%$ povidone-iodine irrigation and surgical mask. Graefes Arch Clin Exp Ophthalmol 251(8):1885-1890. doi:10.1007/s00417-013-2274-y

28. Cheung CS, Wong AW, Lui A, Kertes PJ, Devenyi RG, Lam WC (2012) Incidence of endophthalmitis and use of antibiotic prophylaxis after intravitreal injections. Ophthalmology 119(8):1609-1614. doi:10.1016/j. ophtha.2012.02.014

29. Abell RG, Kerr NM, Allen P, Vote BJ (2012) Intravitreal injections: is there benefit for a theatre setting? Br J Ophthalmol 96(12):1474-1478. doi:10.1136/bjophthalmol-2012-302030

30. Tabandeh H, Boscia F, Sborgia A, Ciraci L, Dayani P, Mariotti C et al (2014) Endophthalmitis associated with intravitreal injections: office-based setting and operating room setting. Retina 34(1):18-23. doi:10.1097/ IAE.0000000000000008

31. Pilli S, Kotsolis A, Spaide RF, Slakter J, Freund KB, Sorenson J et al (2008) Endophthalmitis associated with intravitreal anti-vascular endothelial growth factor therapy injections in an office setting. Am J Ophthalmol 145(5):879-882. doi:10.1016/j.ajo.2007.12.036

32. Fineman MS, Hsu J, Spirn MJ, Kaiser RS (2013) Bimanual assisted eyelid retraction technique for intravitreal injections. Retina 33(9):1968-1970. doi:10.1097/IAE.0b013e318287da92

33. Englander M, Chen TC, Paschalis El, Miller JW, Kim IK (2013) Intravitreal injections at the Massachusetts Eye and Ear Infirmary: analysis of treatment indications and postinjection endophthalmitis rates. $\mathrm{Br} J$ Ophthalmol 97(4):460-465. doi:10.1136/bjophthalmol-2012-302435

34. The American Society of Retina Specialists (ASRS) (2013) Preferences and trends (PAT) surveys. http://www.asrs.org/asrs-community/patsurvey. Accessed 17 Nov 2013

35. Doshi RR, Bakri SJ, Fung AE (2011) Intravitreal injection technique. Semin Ophthalmol. 26(3):104-113. doi:10.3109/08820538.2010.541318

36. Ziemssen F, Wiedemann P, Kampik A, Holz F, Bartz-Schmidt KU (2009) Intravitreal injections of medications in Germany. Contract situation and legal conditions. Ophthalmologe 106(5):465-470. doi:10.1007/ s00347-009-1964-7

37. Barry P, Behrens-Baumann W, Uwe P, Seal D (2007) ESCRS guidelines on prevention, investigation and management of post-operative endophthalmitis. http://www.escrs.org/vienna2011/programme/handouts/ IC-100/IC-100_Barry_Handout.pdf. Accessed 11 Nov 2013

38. Endophthalmitis Study Group ESoC (2007) Refractive S. Prophylaxis of postoperative endophthalmitis following cataract surgery: results of the ESCRS multicenter study and identification of risk factors. J Cataract Refract Surg 33(6):978-988. doi:10.1016/j.jcrs.2007.02.032

39. Smalley KB, Warren JC, Klibert J (2012) Health risk behaviors in insured and uninsured community health center patients in the rural US South. Rural Remote Health 12:2123

40. Tanner J, Swarbrook S, Stuart J (2008) Surgical hand antisepsis to reduce surgical site infection. Cochrane Database Syst Rev 1:CD004288. doi:10.1002/14651858.CD004288.pub2

41. Widmer AF, Rotter M, Voss A, Nthumba P, Allegranzi B, Boyce J et al (2010) Surgical hand preparation: state-of-the-art. J Hosp Infect 74(2):112-122. doi:10.1016/j.jhin.2009.06.020

42. Rotter ML, Kampf G, Suchomel M, Kundi M (2007) Population kinetics of the skin flora on gloved hands following surgical hand disinfection with 3 propanol-based hand rubs: a prospective, randomized, double-blind trial. Infect Control Hosp Epidemiol 28(3):346-350. doi:10.1086/510865

43. Huynh NT, Commens CA (2002) Scrubbing for cutaneous procedures can be hazardous. Australas J Dermatol 43(2):102-104

44. Pietsch H (2001) Hand antiseptics: rubs versus scrubs, alcoholic solutions versus alcoholic gels. J Hosp Infect 48(Suppl A):S33-S36

45. Grayson ML, Ballard SA, Gao W, Khumra S, Ward P, Johnson PD et al (2012) Quantitative efficacy of alcohol-based handrub against vancomycin-resistant enterococci on the hands of human volunteers. Infect Control Hosp Epidemiol 33(1):98-100. doi:10.1086/663342

46. Ghorbani A, Shahrokhi A, Soltani Z, Molapour A, Shafikhani M (2012) Comparison of surgical hand scrub and alcohol surgical hand rub on reducing hand microbial burden. J Perioper Pract. 22(2):67-70

47. Saloojee H, Steenhoff A (2001) The health professional's role in preventing nosocomial infections. Postgrad Med J 77(903):16-19
48. Green-Simms AE, Ekdawi NS, Bakri SJ (2011) Survey of intravitreal injection techniques among retinal specialists in the United States. Am J Ophthalmol 151(2):329-332. doi:10.1016/j.ajo.2010.08.039

49. Shah SU, Koenig MJ, Dacquay Y, Mozayan A, Hubschman JP (2013) Assessment of the risk of needlestick injuries associated with intravitreal injections. Retina. doi:10.1097/IAE.0b013e3182a2f523

50. Anijeet DR, Hanson RJ, Bhagey J, Bates RA (2007) National survey of the technique of intravitreal triamcinolone injection in the United Kingdom. Eye 21(4):480-486. doi:10.1038/sj.eye.6702232

51. Hebl JR (2006) The importance and implications of aseptic techniques during regional anesthesia. Reg Anesth Pain Med 31(4):311-323. doi:10.1016/j.rapm.2006.04.004

52. Miller KM, Apt L (1993) Unsuspected glove perforation during ophthalmic surgery. Arch Ophthalmol 111(2):186-193

53. Olsen RJ, Lynch P, Coyle MB, Cummings J, Bokete T, Stamm WE (1993) Examination gloves as barriers to hand contamination in clinical practice. JAMA 270(3):350-353

54. Stock C, Veyrier M, Raberin H, Fascia P, Rayet I, Lavocat MP et al (2012) Severe cutaneous aspergillosis in a premature neonate linked to nonsterile disposable glove contamination? Am J Infect Control 40(5):465467. doi:10.1016/j.ajic.2011.05.013

55. Bhavsar AR, Googe JM Jr, Stockdale CR, Bressler NM, Brucker AJ, Elman MJ et al (2009) Risk of endophthalmitis after intravitreal drug injection when topical antibiotics are not required: the diabetic retinopathy clinical research network laser-ranibizumab-triamcinolone clinical trials. Arch Ophthalmol 127(12):1581-1583. doi:10.1001/ archophthalmol.2009.304

56. Kim SJ, Chomsky AS, Sternberg P Jr (2013) Reducing the risk of endophthalmitis after intravitreous injection. JAMA Ophthalmol 131(5):674675. doi:10.1001/jamaophthalmol.2013.2914

57. Flores A (2008) Sterile versus non-sterile glove use and aseptic technique. Nurs Stand. 23(6):35-39. doi:10.7748/ns2008.10.23.6.35.c6707

58. Crompton DO (1961) Avoidance of the use of gloves during ophthalmic surgery. Trans Ophthalmol Soc Aust. 21:88-97

59. Perelman VS, Francis GJ, Rutledge T, Foote J, Martino F, Dranitsaris G (2004) Sterile versus nonsterile gloves for repair of uncomplicated lacerations in the emergency department: a randomized controlled trial. Ann Emerg Med 43(3):362-370. doi:10.1016/S0196064403009697

60. Xia Y, Cho S, Greenway HT, Zelac DE, Kelley B (2011) Infection rates of wound repairs during Mohs micrographic surgery using sterile versus nonsterile gloves: a prospective randomized pilot study. Dermatol Surg 37(5):651-656. doi:10.1111/j.1524-4725.2011.01949.x

61. Hepner DL (2006) Gloved and masked-will gowns be next? The role of asepsis during neuraxial instrumentation. Anesthesiology 105(2):241-243

62. Raad II, Hohn DC, Gilbreath BJ, Suleiman N, Hill LA, Bruso PA et al (1994) Prevention of central venous catheter-related infections by using maximal sterile barrier precautions during insertion. Infect Control Hosp Epidemiol 15(4 Pt 1):231-238

63. Alwitry A, Jackson $\mathrm{E}$, Chen H, Holden R (2002) The use of surgical facemasks during cataract surgery: is it necessary? Br J Ophthalmol 86(9):975-977. doi:10.1136/bjo.86.9.975

64. Moloney TP, Park J (2014) Microbiological isolates and antibiotic sensitivities in culture-proven endophthalmitis: a 15-year review. $\mathrm{Br}$ Ophthalmol 98(11):1492-1497. doi:10.1136/bjophthalmol-2014-305030

65. Facklam R (2002) What happened to the streptococci: overview of taxonomic and nomenclature changes. Clin Microbiol Rev 15(4):613-630

66. Frandsen EV, Pedrazzoli V, Kilian M (1991) Ecology of viridans streptococci in the oral cavity and pharynx. Oral Microbiol Immunol 6(3):129-133

67. Kim SJ, Toma HS, Midha NK, Cherney EF, Recchia FM, Doherty TJ (2010) Antibiotic resistance of conjunctiva and nasopharynx evaluation study: a prospective study of patients undergoing intravitreal injections. Ophthalmology 117(12):2372-2378. doi:10.1016/j. ophtha.2010.03.034

68. Yin VT, Weisbrod DJ, Eng KT, Schwartz C, Kohly R, Mandelcorn E et al (2013) Antibiotic resistance of ocular surface flora with repeated use of a topical antibiotic after intravitreal injection. JAMA Ophthalmol. 131(4):456-461. doi:10.1001/jamaophthalmol.2013.2379 
69. Moss JM, Sanislo SR, Ta CN (2009) A prospective randomized evaluation of topical gatifloxacin on conjunctival flora in patients undergoing intravitreal injections. Ophthalmology 116(8):1498-1501. doi:10.1016/j. ophtha.2009.02.024

70. Wen JC, McCannel CA, Mochon AB, Garner OB (2011) Bacterial dispersal associated with speech in the setting of intravitreous injections. Arch Ophthalmol 129(12):1551-1554. doi:10.1001/archophthalmol.2011.227

71. Doshi RR, Leng T, Fung AE (2012) Reducing oral flora contamination of intravitreal injections with face mask or silence. Retina. 32(3):473-476. doi:10.1097/IAE.0B013E31822C2958

72. Friedman DA, Lindquist TP, Mason JO 3rd, McGwin G (2014) Needle contamination in the setting of intravitreal injections. Retina 34(5):929934. doi:10.1097/IAE.0000000000000067

73. Shewmaker PL, Gertz RE Jr, Kim CY, de Fijter S, DiOrio M, Moore MR et al (2010) Streptococcus salivarius meningitis case strain traced to oral flora of anesthesiologist. J Clin Microbiol 48(7):2589-2591. doi:10.1128/ JCM.00426-10

74. Trautmann M, Lepper PM, Schmitz FJ (2002) Three cases of bacterial meningitis after spinal and epidural anesthesia. Eur J Clin Microbiol Infect Dis 21(1):43-45

75. Veringa $E$, van Belkum A, Schellekens H (1995) latrogenic meningitis by Streptococcus salivarius following lumbar puncture. J Hosp Infect 29(4):316-318

76. Baer ET (2006) Post-dural puncture bacterial meningitis. Anesthesiology 105(2):381-393

77. Coatsworth NR, Huntington PG, Giuffre B, Kotsiou G (2013) The doctor and the mask: iatrogenic septic arthritis caused by Streptoccocus mitis. Med J Aust 198(5):285-286

78. Reeves KD, Horvat RT (2010) Aerosolized alpha-hemolytic Streptococcus as a cause of knee sepsis after intra-articular injection: predisposing factors. Am J Phys Med Rehabil 89(1):77-82. doi:10.1097/ PHM.0b013e3181c1ee3c

79. Sherertz RJ, Reagan DR, Hampton KD, Robertson KL, Streed SA, Hoen HM et al (1996) A cloud adult: the Staphylococcus aureus-virus interaction revisited. Ann Intern Med 124(6):539-547

80. Orr NW (1981) Is a mask necessary in the operating theatre? Ann R Coll Surg Engl 63(6):390-392

81. Tunevall TG (1991) Postoperative wound infections and surgical face masks: a controlled study. World J Surg. 15(3):383-387 (discussion 7-8)

82. Webster J, Croger S, Lister C, Doidge M, Terry MJ, Jones I (2010) Use of face masks by non-scrubbed operating room staff: a randomized controlled trial. ANZ J Surg. 80(3):169-173. doi:10.1111/j.1445-2197.2009.05200.x

83. Philips BJ, Fergusson S, Armstrong P, Anderson FM, Wildsmith JA (1992) Surgical face masks are effective in reducing bacterial contamination caused by dispersal from the upper airway. Br J Anaesth 69(4):407-408

84. Kuriyan AE, Weiss KD, Flynn HW Jr, Smiddy WE, Berrocal AM, Albini TA et al (2014) Endophthalmitis caused by streptococcal species: clinical settings, microbiology, management, and outcomes. Am J Ophthalmol 57(4):774-780 e1. doi:10.1016/j.ajo.2013.12.026

85. Jacobs DJ, Leng T, Flynn HW Jr, Shi W, Miller D, Gedde SJ (2011) Delayed-onset bleb-associated endophthalmitis: presentation and outcome by culture result. Clin Ophthalmol. 5:739-744. doi:10.2147/ OPTH.S17975

86. Leng T, Miller D, Flynn HW Jr, Jacobs DJ, Gedde SJ (2011) Delayed-onset bleb-associated endophthalmitis (1996-2008): causative organisms and visual acuity outcomes. Retina. 31(2):344-352. doi:10.1097/ IAE.0b013e3181e09810

87. Schimel AM, Scott IU, Flynn HW Jr (2011) Endophthalmitis after intravitreal injections: should the use of face masks be the standard of care? Arch Ophthalmol 129(12):1607-1609. doi:10.1001/ archophthalmol.2011.370

88. Kamalarajah S, Ling R, Silvestri G, Sharma NK, Cole MD, Cran G et al (2007) Presumed infectious endophthalmitis following cataract surgery in the UK: a case-control study of risk factors. Eye. 21(5):580-586. doi:10.1038/sj.eye.6702368

89. Schachat AP, Rosenfeld PJ, Liesegang TJ, Stewart MW (2012) Endophthalmitis is not a "never event". Ophthalmology 119(8):1507-1508. doi:10.1016/j.ophtha.2012.03.048
90. Wildsmith JA (1993) Face masks and spinal anaesthesia [reply]. Br J Anaesth 70(2):239

91. Schiff FS (1990) The shouting surgeon as a possible source of endophthalmitis. Ophthal Surg. 21(6):438-440

92. Ahmed Y, Scott IU, Pathengay A, Bawdekar A, Flynn HW Jr (2014) Povidone-iodine for endophthalmitis prophylaxis. Am J Ophthalmol 157(3):503-504. doi:10.1016/j.ajo.2013.12.001

93. de Kaspar HM, Chang RT, Singh K, Egbert PR, Blumenkranz MS, Ta CN (2005) Prospective randomized comparison of 2 different methods of $5 \%$ povidone-iodine applications for anterior segment intraocular surgery. Arch Ophthalmol. 123(2):161-165. doi:10.1001/archopht.123.2.161

94. Barry AL, Fuchs PC, Brown SD (1999) Lack of effect of antibiotic resistance on susceptibility of microorganisms to chlorhexidine gluconate or povidone iodine. Euro J Clin Microbiol Infect Dis 18(12):920-921. doi:10.1007/s100960050434

95. Anderson MJ, Horn ME, Lin YC, Parks PJ, Peterson ML (2010) Efficacy of concurrent application of chlorhexidine gluconate and povidone iodine against six nosocomial pathogens. Am J Infect Control 38(10):826-831. doi:10.1016/j.ajic.2010.06.022

96. Ta CN (2004) Minimizing the risk of endophthalmitis following intravitreous injections. Retina. 24(5):699-705

97. Isenberg SJ, Apt L, Campeas D (2002) Ocular applications of povidoneiodine. Dermatology 204(Suppl 1):92-95. doi:57733

98. Apt L, Isenberg S, Yoshimori R, Paez JH (1984) Chemical preparation of the eye in ophthalmic surgery. III. Effect of povidone-iodine on the conjunctiva. Arch Ophthalmol 102(5):728-729

99. Speaker MG, Menikoff JA (1991) Prophylaxis of endophthalmitis with topical povidone-iodine. Ophthalmology 98(12):1769-1775

100. Wykoff CC, Flynn HW Jr, Han DP (2011) Allergy to povidone-iodine and cephalosporins: the clinical dilemma in ophthalmic use. Am J Ophthalmol 151(1):4-6. doi:10.1016/j.ajo.2010.08.044

101. Coakley FV, Panicek DM (1997) lodine allergy: an oyster without a pearl? AJR Am J Roentgenol 169(4):951-952. doi:10.2214/ajr.169.4.9308442

102. Jiang J, Wu M, Shen T (2009) The toxic effect of different concentrations of povidone iodine on the rabbit's cornea. Cutan Ocul Toxicol 28(3):119-124. doi:10.1080/15569520903080511

103. Wykoff CC, Flynn HW, Jr., Rosenfeld PJ (2011) Prophylaxis for endophthalmitis following intravitreal injection: antisepsis and antibiotics. Am J Ophthalmol 152(5):717-719 e2. doi:10.1016/j.ajo.2011.07.002

104. Trost LW, Kivilcim M, Peyman GA, Aydin E, Kazi AA (2007) The effect of intravitreally injected povidone-iodine on Staphylococcus epidermidis in rabbit eyes. J Ocul Pharmacol Ther 23(1):70-77. doi:10.1089/ jop.2006.0076

105. Whitacre MM, Crockett RS (1990) Tolerance of intravitreal povidoneiodine in rabbit eyes. Curr Eye Res 9(8):725-732

106. Schabelman E, Witting M (2010) The relationship of radiocontrast, iodine, and seafood allergies: a medical myth exposed. J Emerg Med 39(5):701-707. doi:10.1016/j.jemermed.2009.10.014

107. Safar A, Dellimore MC (2007) The effect of povidone iodine flush versus drops on conjunctival colonization before intravitreal injections. Int Ophthalmol 27(5):307-312. doi:10.1007/s10792-007-9073-6

108. Aiello LP, Brucker AJ, Chang S, Cunningham ET Jr, D'Amico DJ, Flynn HW Jr et al (2004) Evolving guidelines for intravitreous injections. Retina 24(5 Suppl):S3-S19

109. Avery RL, Bakri SJ, Blumenkranz MS, Brucker AJ, Cunningham ET Jr, D'Amico DJ et al (2014) Intravitreal injection technique and monitoring: updated guidelines of an expert panel. Retina. 34(Suppl 12):S1-S18. doi:10.1097/IAE.0000000000000399

110. Ferguson AW, Scott JA, McGavigan J, Elton RA, McLean J, Schmidt U et al (2003) Comparison of 5\% povidone-iodine solution against $1 \%$ povidone-iodine solution in preoperative cataract surgery antisepsis: a prospective randomised double blind study. $\mathrm{Br} J$ Ophthalmol 87(2):163-167

111. Berkelman RL, Holland BW, Anderson RL (1982) Increased bactericidal activity of dilute preparations of povidone-iodine solutions. J Clin Microbiol 15(4):635-639

112. Ta CN, Singh K, Egbert PR, de Kaspar HM (2008) Prospective comparative evaluation of povidone-iodine (10\% for 5 minutes versus $5 \%$ for 1 minute) as prophylaxis for ophthalmic surgery. J Cataract Refract Surg 34(1):171-172. doi:10.1016/j.jcrs.2007.08.035 
113. van Rooij J, Boks AL, Sprenger A, Ossewaarde JM, van Meurs JC (2011) The concentration of povidone-iodine for preoperative disinfection: relation to endophthalmitis incidence. Am J Ophthalmol 152(2):321. doi:10.1016/j.ajo.2011.03.036

114. Friedman DA, Mason JO 3rd, Emond T, McGwin G Jr (2013) Povidoneiodine contact time and lid speculum use during intravitreal injection. Retina. 33(5):975-981. doi:10.1097/IAE.0b013e3182877585

115. Apt L, Isenberg SJ, Yoshimori R, Chang A, Lam GC, Wachler B et al (1995) The effect of povidone-iodine solution applied at the conclusion of ophthalmic surgery. Am J Ophthalmol 119(6):701-705

116. Houang ET, Gilmore OJ, Reid C, Shaw EJ (1976) Absence of bacterial resistance to povidone iodine. J Clin Pathol 29(8):752-755

117. Kunisada T, Yamada K, Oda S, Hara O (1997) Investigation on the efficacy of povidone-iodine against antiseptic-resistant species. Dermatology 195(Suppl 2):14-18

118. Hsu J, Gerstenblith AT, Garg SJ, Vander JF (2014) Conjunctival flora antibiotic resistance patterns after serial intravitreal injections without postinjection topical antibiotics. Am J Ophthalmol. 157(3):514-518 e1. doi:10.1016/j.ajo.2013.10.003

119. Emilson CG (1977) Susceptibility of various microorganisms to chlorhexidine. Scand J Dent Res 85(4):255-265

120. Barkana Y, Almer Z, Segal O, Lazarovitch Z, Avni I, Zadok D (2005) Reduction of conjunctival bacterial flora by povidone-iodine, ofloxacin and chlorhexidine in an outpatient setting. Acta Ophthalmol Scand 83(3):360-363. doi:10.1111/j.1600-0420.2005.00414.x

121. Yokoyama Y, Makino S, Ibaraki N (2008) Comparison in effectiveness of sterilization between chlorhexidine gluconate and povidone-iodine. Nihon Ganka Gakkai Zasshi 112(2):148-151

122. Hamill MB, Osato MS, Wilhelmus KR (1984) Experimental evaluation of chlorhexidine gluconate for ocular antisepsis. Antimicrob Agents Chemother 26(6):793-796

123. Burstein NL (1980) Preservative cytotoxic threshold for benzalkonium chloride and chlorhexidine digluconate in cat and rabbit corneas. Invest Ophthalmol Vis Sci 19(3):308-313

124. Gasset AR, Ishii Y (1975) Cytotoxicity of chlorhexidine. Can J Ophthalmol 10(1):98-100

125. Varley GA, Meisler DM, Benes SC, McMahon JT, Zakov ZN, Fryczkowski A (1990) Hibiclens keratopathy. A clinicopathologic case report. Cornea 9(4):341-346

126. Dart JK, Saw VP, Kilvington S (2009) Acanthamoeba keratitis: diagnosis and treatment update 2009. Am J Ophthalmol 148(4):487-99 e2. doi:10.1016/j.ajo.2009.06.009

127. Anders N, Wollensak J (1997) Inadvertent use of chlorhexidine instead of balanced salt solution for intraocular irrigation. J Cataract Refract Surg 23(6):959-962

128. Green K, Livingston V, Bowman K, Hull DS (1980) Chlorhexidine effects on corneal epithelium and endothelium. Arch Ophthalmol 98(7):1273-1278

129. Klebe S, Anders N, Wollensak J (1998) Inadvertent use of chlorhexidine as intraocular irrigation solution. J Cataract Refract Surg 24(6):729-730

130. Horner C, Mawer D, Wilcox M (2012) Reduced susceptibility to chlorhexidine in staphylococci: is it increasing and does it matter? J Antimicrob Chemother 67(11):2547-2559. doi:10.1093/jac/dks284

131. Langgartner J, Linde HJ, Lehn N, Reng M, Scholmerich J, Gluck T (2004) Combined skin disinfection with chlorhexidine/propanol and aqueous povidone-iodine reduces bacterial colonisation of central venous catheters. Intensive Care Med 30(6):1081-1088. doi:10.1007/ s00134-004-2282-9

132. Guzel A, Ozekinci T, Ozkan U, Celik Y, Ceviz A, Belen D (2009) Evaluation of the skin flora after chlorhexidine and povidone-iodine preparation in neurosurgical practice. Surg Neurol 71(2):207-210. doi:10.1016/j. surneu.2007.10.026 (discussion 10)

133. Isenberg S, Apt L, Yoshimuri R (1983) Chemical preparation of the eye in ophthalmic surgery. I. Effect of conjunctival irrigation. Arch Ophthalmol 101(5):761-763

134. Boes DA, Lindquist TD, Fritsche TR, Kalina RE (1992) Effects of povidoneiodine chemical preparation and saline irrigation on the perilimbal flora. Ophthalmology 99(10):1569-1574

135. Page MA, Fraunfelder FW (2009) Safety, efficacy, and patient acceptability of lidocaine hydrochloride ophthalmic gel as a topical ocular anesthetic for use in ophthalmic procedures. Clin Ophthalmol. 3:601-609
136. Kozak I, Cheng L, Freeman WR (2005) Lidocaine gel anesthesia for intravitreal drug administration. Retina 25(8):994-998

137. Boden JH, Myers ML, Lee T, Bushley DM, Torres MF (2008) Effect of lidocaine gel on povidone-iodine antisepsis and microbial survival. J Cataract Refract Surg 34(10):1773-1775. doi:10.1016/j.jcrs.2008.05.056

138. Miller JJ, Scott IU, Flynn HW Jr, Smiddy WE, Newton J, Miller D (2005) Acute-onset endophthalmitis after cataract surgery (2000-2004): incidence, clinical settings, and visual acuity outcomes after treatment. Am J Ophthalmol 139(6):983-987. doi:10.1016/j.ajo.2005.01.025

139. Inman ZD, Anderson NG (2011) Incidence of endophthalmitis after intravitreal injection of antivascular endothelial growth factor medications using topical lidocaine gel anesthesia. Retina 31(4):669-672. doi:10.1097/IAE.0b013e3181ef463d

140. Doshi RR, Leng T, Fung AE (2011) Povidone-iodine before lidocaine ge anesthesia achieves surface antisepsis. Ophthal Surg Lasers Imaging. 42(4):346-349. doi:10.3928/15428877-20110210-02

141. Dahl DE, Dahl T Jr, Lane G, Ferguson D (2008) Does lidocaine gel decrease the effectiveness of a povidone-iodine prep? Invest Ophthalmol Vis Sci 49(5):5629

142. Lad EM, Maltenfort MG, Leng T (2012) Effect of lidocaine gel anesthesia on endophthalmitis rates following intravitreal injection. Ophthal Surg Lasers Imaging. 43(2):115-120. doi:10.3928/15428877-20120119-01

143. Tustin A, Kim SJ, Chomsky A, Hubbard GB 3rd, Sheng J (2014) Antibacterial properties of $2 \%$ lidocaine and reduced rate of endophthalmitis after intravitreal injection. Retina 34(5):935-942. doi:10.1097/ IAE.0000000000000014

144. Scott IU, Flynn HW Jr (2007) Reducing the risk of endophthalmitis following intravitreal injections. Retina. 27(1):10-12. doi:10.1097/ IAE.0b013e3180307271

145. Isenberg SJ, Apt L, Yoshimori R, Khwarg S (1985) Chemical preparation of the eye in ophthalmic surgery. IV. Comparison of povidone-iodine on the conjunctiva with a prophylactic antibiotic. Arch Ophthalmol 103(9):1340-1342

146. Ta CN, Egbert PR, Singh K, Shriver EM, Blumenkranz MS, de Kaspar HM (2002) Mino De H. Prospective randomized comparison of 3-day versus 1-hour preoperative ofloxacin prophylaxis for cataract surgery. Ophthalmology. 109(11):2036-2040 (discussion 40-1)

147. Halachmi-Eyal O, Lang Y, Keness Y, Miron D (2009) Preoperative topical moxifloxacin $0.5 \%$ and povidone-iodine $5.0 \%$ versus povidone-iodine $5.0 \%$ alone to reduce bacterial colonization in the conjunctival sac. J Cataract Refract Surg 35(12):2109-2114. doi:10.1016/j.jcrs.2009.06.038

148. Bhatt SS, Stepien KE, Joshi K (2011) Prophylactic antibiotic use after intravitreal injection: effect on endophthalmitis rate. Retina. 31(10):2032-2036. doi:10.1097/IAE.0b013e31820f4b4f

149. Bhavsar AR, Stockdale CR, Ferris FL 3rd, Brucker AJ, Bressler NM, Glassman AR et al (2012) Update on risk of endophthalmitis after intravitreal drug injections and potential impact of elimination of topical antibiotics. Arch Ophthalmol 130(6):809-810. doi:10.1001/ archophthalmol.2012.227

150. Falavarjani KG, Modarres M, Hashemi M, Parvaresh MM, Naseripour M, Zare-Moghaddam A et al (2013) Incidence of acute endophthalmitis after intravitreal bevacizumab injection in a single clinical center. Retina 33(5):971-974. doi:10.1097/IAE.0b013e31826f0675

151. Miller D, Flynn PM, Scott IU, Alfonso EC, Flynn HW Jr (2006) In vitro fluoroquinolone resistance in staphylococcal endophthalmitis isolates. Arch Ophthalmol 124(4):479-483. doi:10.1001/archopht.124.4.479

152. Schimel AM, Miller D, Flynn HW (2012) Evolving fluoroquinolone resistance among coagulase-negative Staphylococcus isolates causing endophthalmitis. Arch Ophthalmol 130(12):1617-1618. doi:10.1001/ archophthalmol.2012.2348

153. Schimel AM, Miller D, Flynn HW Jr (2013) Endophthalmitis isolates and antibiotic susceptibilities: a 10-year review of culture-proven cases. Am J Ophthalmol 156(1):50-52 e1. doi:10.1016/j.ajo.2013.01.027

154. Kim SJ, Toma HS (2011) Ophthalmic antibiotics and antimicrobial resistance a randomized, controlled study of patients undergoing intravitreal injections. Ophthalmology 118(7):1358-1363. doi:10.1016/j. ophtha.2010.12.014

155. Kim SJ, Toma HS (2011) Antimicrobial resistance and ophthalmic antibiotics: 1-year results of a longitudinal controlled study of patients undergoing intravitreal injections. Arch Ophthalmol 129(9):1180-1188 doi:10.1001/archophthalmol.2011.213 
156. Dave SB, Toma HS, Kim SJ (2011) Ophthalmic antibiotic use and multidrug-resistant staphylococcus epidermidis: a controlled, longitudinal study. Ophthalmology 118(10):2035-2040. doi:10.1016/j. ophtha.2011.03.017

157. Milder E, Vander J, Shah C, Garg S (2012) Changes in antibiotic resistance patterns of conjunctival flora due to repeated use of topical antibiotics after intravitreal injection. Ophthalmology 119(7):1420-1424. doi:10.1016/j.ophtha.2012.01.016

158. Mino De Kaspar H, Hoepfner AS, Engelbert M, Thiel M, Ta CN, Mette $M$ et al (2001) Antibiotic resistance pattern and visual outcome in experimentally-induced Staphylococcus epidermidis endophthalmitis in a rabbit model. Ophthalmology 108(3):470-478

159. Dave SB, Toma HS, Kim SJ (2013) Changes in ocular flora in eyes exposed to ophthalmic antibiotics. Ophthalmology 120(5):937-941. doi:10.1016/j.ophtha.2012.11.005

160. Yalvac IS, Basci NE, Bozkurt A, Duman S (2003) Penetration of topically applied ciprofloxacin and ofloxacin into the aqueous humor and vitreous. J Cataract Refract Surg 29(3):487-491. doi:10.1016/ S0886-3350(02)01538-9

161. Costello P, Bakri SJ, Beer PM, Singh RJ, Falk NS, Peters GB et al (2006) Vitreous penetration of topical moxifloxacin and gatifloxacin in humans. Retina 26(2):191-195

162. Gragoudas ES, Adamis AP, Cunningham ET Jr, Feinsod M, Guyer DR, Group VISiONCT (2004) Pegaptanib for neovascular age-related macular degeneration. N Engl J Med 351(27):2805-2816. doi:10.1056/ NEJMoa042760

163. Principe $\mathrm{AH}$ (2008) Update on intravitreal injections. Tech Ophthalmol 6(3):83-87

164. Tailor R, Beasley R, Yang Y, Narendran N (2011) Evaluation of patients' experiences at different stages of the intravitreal injection procedurewhat can be improved? Clin Ophthalmol 5:1499-1502. doi:10.2147/ OPTH.S24358

165. Stewart MW (2014) To the Editor. Retina 34(4):e11-e13

166. Shrier EM (2014) Cotton-tip applicator lid retraction technique for controlled intravitreal injection. Retina. 34(6):1244-1246. doi:10.1097/ IAE.0000000000000219

167. Mason RW (2013) Use of a desmarres retractor for upper lid and lash isolation during intravitreal injections. Retina 33(10):2175-2176. doi:10.1097/IAE.0b013e3182999a1b

168. Shah CP, Garg SJ, Vander JF, Brown GC, Kaiser RS, Haller JA et al (2011) Outcomes and risk factors associated with endophthalmitis after intravitreal injection of anti-vascular endothelial growth factor agents. Ophthalmology 118(10):2028-2034. doi:10.1016/j.ophtha.2011.02.034

169. Usman Saeed M, Batra R, Qureshi F, Clark D (2011) Reflux of drug during intra-vitreal anti-VEGF therapies. Semin Ophthalmol 26(6):357-360. doi: 10.3109/08820538.2011.588648

170. Cortez RT, Ramirez G, Collet L, Thakuria P, Giuliari GP (2010) Intravitreous bevacizumab injection: an experimental study in New Zealand white rabbits. Arch Ophthalmol 128(7):884-887. doi:10.1001/ archophthalmol.2010.139

171. Christoforidis JB, Williams MM, Epitropoulos FM, Knopp MV (2013) Subconjunctival bleb that forms at the injection site after intravitreal injection is drug, not vitreous. Clin Experiment Ophthalmol 41(6):614-615. doi:10.1111/ceo.12074

172. Brodie FL, Ruggiero J, Ghodasra DH, Hui JZ, VanderBeek BL, Brucker AJ (2014) Volume and composition of reflux after intravitreal injection. Retina. 34(7):1473-1476. doi:10.1097/IAE.0000000000000098

173. Saeed MU, Qureshi F, Batra R, Clark D (2011) Effect of reflux of drug during intravitreal anti-VEGF therapies on foveal thickness. Semin Ophthalmol. 26(2):61-63. doi:10.3109/08820538.2011.559518

174. Chen SD, Mohammed Q, Bowling B, Patel CK (2004) Vitreous wick syndrome-a potential cause of endophthalmitis after intravitreal injection of triamcinolone through the pars plana. Am J Ophthalmol. 137(6):1159-1160. doi:10.1016/j.ajo.2004.01.028 (author reply 60-1)

175. Turgut B, Demir T, Celiker U (2009) The effects of injection site on the reflux following intravitreal injections. J Clin Med Res. 1(5):280-284. doi:10.4021/jocmr2009.12.1280

176. Cassar J, Smith T, Kwan T (2012) Intravitreal inoculation of cotton after bevacizumab (Avastin) injection. Arch Ophthalmol 130(1):126
177. Bdour MD, Ali ZR (2014) Intravitreal foreign body following intravitreal anti-VEGF injection: a case report. Eye 28(2):244-245. doi:10.1038/ eye.2013.250

178. Rodrigues EB, Meyer CH, Grumann A Jr, Shiroma H, Aguni JS, Farah ME (2007) Tunneled scleral incision to prevent vitreal reflux after intravitreal injection. Am J Ophthalmol 143(6):1035-1037. doi:10.1016/j. ajo.2007.01.035

179. Knecht PB, Michels S, Sturm V, Bosch MM, Menke MN (2009) Tunnelled versus straight intravitreal injection: intraocular pressure changes, vitreous reflux, and patient discomfort. Retina. 29(8):1175-1181. doi:10.1097/IAE.0b013e3181aade74

180. Ozkaya A, Alkin Z, Celik U, Yuksel K, Ozgurhan EB, Agca A et al (2013) Comparing the effects of three different intravitreal injection techniques on vitreous reflux and intraocular pressure. J Ocul Pharmacol Ther 29(3):325-329. doi:10.1089/jop.2012.0144

181. Pulido JS, Pulido CM, Bakri SJ, McCannel CA, Cameron JD (2007) The use of 31-gauge needles and syringes for intraocular injections. Eye. 21(6):829-830. doi:10.1038/sj.eye.6702514

182. Van Went C, Le Tien V, Mimoun G, Leveziel N, Parier V, Voigt M et al (2008) Comparison between 32 G vs 30 G needles used for intra vitreous injection (IVT). J Fr Ophtalmol 31(Supplement 1):99-100

183. Hubschman JP, Coffee RE, Bourges JL, Yu F, Schwartz SD (2010) Experimental model of intravitreal injection techniques. Retina. 30(1):167-173. doi:10.1097/IAE.0b013e3181b094cf

184. Hoang QV, Jung JJ, Mrejen S, Freund KB (2014) Influence of axial length and postinjection reflux on sustained intraocular pressure elevation as a result of intravitreal anti-vascular endothelial growth factor therapy. Retina. 34(3):519-524. doi:10.1097/IAE.0000000000000039

185. Pang CE, Mrejen S, Hoang QV, Sorenson JA, Freund KB (2015) Association between needle size, postinjection reflux, and intraocular pressure spikes after intravitreal injections. Retina. doi:10.1097/ IAE.0000000000000476

186. Centre for Disease Control and Prevention (2013) Injection safety: medication preparation questions. http://www.cdc.gov/injectionsafety/ providers/provider_faqs_med-prep.html. Accessed 31 Oct 2013

187. Buckley T, Dudley SM, Donowitz LG (1994) Defining unnecessary disinfection procedures for single-dose and multiple-dose vials. Am J Crit Care 3(6):448-451

188. Hilliard JG, Cambronne ED, Kirsch JR, Aziz MF (2013) Barrier protection capacity of flip-top pharmaceutical vials. J Clin Anesth 25(3):177-180. doi:10.1016/j.jclinane.2012.07.006

189. Tabatabaii A, Ahmadraji A, Khodabande A, Mansouri M (2013) Acute bilateral endophthalmitis following bilateral intravitreal bevacizumab (avastin) injection. Middle East Afr J Ophthalmol 20(1):87-88. doi:10.4103/0974-9233.106402

190. Bakri SJ, Risco M, Edwards AO, Pulido JS (2009) Bilateral simultaneous intravitreal injections in the office setting. Am J Ophthalmol 48(1):66-69 e1. doi:10.1016/j.ajo.2009.02.013

191. Shah GY, Ambatipudi S, Fernandes M, Lakshmipathy M, Varma PV, Sachdeva $V$ et al (2010) We congratulate the authors for publishing their data on bilateral consecutive intravitreal injections administered in their office. Retina. 30(8):1325-1326. doi:10.1097/IAE.0b013e3181e7985c

\section{(author reply 6-7)}

192. Lima LH, Zweifel SA, Engelbert M, Sorenson JA, Slakter JS, Cooney MJ et al (2009) Evaluation of safety for bilateral same-day intravitreal injections of antivascular endothelial growth factor therapy. Retina. 29(9):1213-1217. doi:10.1097/IAE.0b013e3181b32d27

193. Mahajan VB, Elkins KA, Russell SR, Boldt HC, Gehrs KM, Weingeist TA et al (2011) Bilateral intravitreal injection of antivascular endothelial growth factor therapy. Retina. 31(1):31-35. doi:10.1097/IAE.0b013e3181ed8c80

194. Woo SJ, Han JM, Ahn J, Heo JW, Yu HG, Chung H et al (2012) Bilateral same-day intravitreal injections using a single vial and molecular bacterial screening for safety surveillance. Retina. 32(4):667-671. doi:10.1097/ IAE.0b013e31822c296b

195. Davis RP, Schefler AC, Murray TG (2010) Concomitant bilateral intravitreal anti-VEGF injections for the treatment of exudative age-related macular degeneration. Clin Ophthalmol. 4:703-707

196. Abu-Yaghi NE, Shokry AN, Abu-Sbeit RH (2014) Bilateral same-session intravitreal injections of anti-vascular endothelial growth factors. Int J Ophthalmol 7(6):1017-1021. doi:10.3980/j.issn.2222-3959.2014.06.20 
197. Chao DL, Gregori NZ, Khandji J, Goldhardt R (2014) Safety of bilateral intravitreal injections delivered in a teaching institution. Expert Opin Drug Deliv 11(7):991-993. doi:10.1517/17425247.2014.909806

198. Goldberg RA, Flynn HW, Isom RF, Miller D, Gonzalez S (2012) An outbreak of Streptococcus endophthalmitis after intravitreal injection of bevacizumab. Am J Ophthalmol 53(2):204-208.e1. doi:10.1016/j. ajo.2011.11.035
199. Moshfeghi AA (2011) Endophthalmitis following intravitreal anti-vascular endothelial growth factor injections for neovascular age-related macular degeneration. Semin Ophthalmol 26(3):139-148. doi:10.3109/0 8820538.2011 .570847

200. Schachat AP (2014) Simultaneous bilateral endophthalmitis after immediate sequential bilateral cataract surgery: what's the risk of functional blindness? Am J Ophthalmol 158(2):410-411. doi:10.1016/j.ajo.2014.05.008
Submit your next manuscript to BioMed Central and take full advantage of:

- Convenient online submission

- Thorough peer review

- No space constraints or color figure charges

- Immediate publication on acceptance

- Inclusion in PubMed, CAS, Scopus and Google Scholar

- Research which is freely available for redistribution

Submit your manuscript at

www.biomedcentral.com/submit 